\title{
ARelevância do Acórdão Bustani do Tribunal Administrativo da OIT para a Consagração do Princípio da Autonomia das Organizações Internacionais
}

\author{
The Relevance of Bustani Judgment of the Administrative Tribunal of the \\ ILO for the consecration of the Principle of Autonomy of International \\ Organizations
}

Karine de Souza Silva

Universidade Federal de Santa Catarina, Florianópolis - SC, Brasil

\begin{abstract}
Resumo: o objetivo deste artigo é destacar a importância do Acórdão "Bustani”, proferido pelo Tribunal Administrativo da Organização Internacional do Trabalho (TAOIT), para a consolidação do princípio da autonomia, considerado um dos elementos constitutivos da personalidade jurídica das Organizações Internacionais. O primeiro tópico apresenta a Organização para a Proibição de Armas Químicas e expõe a narrativa do caso que culminou na deposição do Diretor-Geral e motivou a postulação da demanda com o TAOIT. $\mathrm{Na}$ sequência, figuram os principais contornos do processo, nomeadamente os argumentos das partes, as bases jurídicas e a decisão da Corte. Finalmente, são evidenciados o trajeto de afirmação da autonomia como raison d'être das OIs e a relevância da jurisprudência Bustani.
\end{abstract}

Palavras-chave: Organizações Internacionais. Jurisprudência Bustani. Autonomia.

\begin{abstract}
: the purpose of this article is to highlight the importance of the judgment "Bustani" delivered by the Administrative Tribunal of the International Labour Organization (ILOAT), to consolidate the principle of autonomy, considered as one of the constitutive elements of the legal personality of International Organizations. The first topic presents the Organization for the Prohibition of Chemical Weapons (OPCW) and explains the case that culminated in the dismissal of the Director-General and led to the postulation of the demand before the ILOAT. The second topic shows the main outlines of the process, including the parties' arguments, the legal basis and the decision of the Court. Finally, the article analyses the way of affirmation of autonomy as a raison d'être of International Organizations and presents the relevance of Bustani jurisprudence.
\end{abstract}

Keywords: The Bustani Judgment. International Organizations. Autonomy.

Recebido em: 09/12/2015

Revisado em: 04/04/2016

Aprovado em: 08/05/2016 


\section{Introdução}

O Acordão n. 2.232 do Tribunal Administrativo da Organização Internacional do Trabalho (TAOIT) versou sobre a demanda que opôs o embaixador brasileiro José Maurício Bustani à Organização para a Proibição de Armas Químicas (OPAQ).

A jurisprudência Bustani é um dos divisores de águas no processo de solidificação das bases da personalidade jurídica das Organizações Internacionais (OIs), inaugurado pelo Parecer Folke Bernadotte da Corte Internacional de Justiça, de 1949, que as reconheceu como sujeitos de Direito Internacional Público.

Se o Parecer de 1949 tornou a personalidade jurídica das OIs, uma verdade incontestável, o Acórdão do TAOIT é, também, um marco na medida em que desenvolveu e reforçou um dos atributos essenciais da subjetividade dos organismos multilaterais que é sua autonomia frente aos entes estatais e a independência dos servidores públicos internacionais. O princípio da autonomia preserva a identidade própria que, por sua vez, se manifesta por meio da capacidade das Instituições de expressarem uma volonté distincte e se revela como condição fundamental para o cumprimento das obrigações e dos fins que são decorrentes dos Tratados fundadores.

Nessa ordem de ideias, o presente artigo objetiva apresentar a relevância da Sentença "Bustani”, proferida pelo TAOIT, para a consolidação e o reforço do princípio da autonomia, considerado como um dos elementos constitutivos da personalidade jurídica das Organizações Internacionais.

Para tal, no primeiro tópico contextualiza o nascimento e os objetivos da OPAQ. Na sequência, é apresentada a narrativa do caso que culminou na deposição do Diretor-Geral e motivou a postulação da demanda junto ao Tribunal Administrativo da OIT. Finalmente, são evidenciados o trajeto de afirmação da autonomia como raison d'être das OIs e a relevância da jurisprudência Bustani. 


\section{Narrativa do Caso}

Preliminarmente, é fundamental contextualizar a origem e apresentar o funcionamento da OPAQ, para o melhor entendimento da jurisprudência Bustani. A OPAQ nasceu sob o abrigo do artigo VIII da Convenção para a Proibição das Armas Químicas (CPAQ) que entrou em vigor em $1997^{1}$. No mesmo ano, foi criada a OPAQ, cujo objetivo principal é implementar os termos da Convenção e funcionar como um fórum de consulta e cooperação entre os Estados signatários ${ }^{2}$.

A OPAQ veio à luz com a missão de livrar o mundo completamente das armas químicas. Para tal, a Convenção define quatro premissas: 1) Destruir todo o arsenal existente de armas químicas verificadas internacionalmente pela OPAQ; 2) Monitorar as indústrias químicas para prevenir a produção de novas armas; 3) Oferecer assistência e proteção aos Estados membros contra ameaças químicas; 4) Fomentar a cooperação internacional para reforçar a implementação da Convenção e promover o uso pacífico da química. (OPCW, 2015).

A Organização é formada por três órgãos: a Conferência dos Estados-membros (Conferência); o Conselho Executivo (Conselho); e o Secretariado Técnico, que é liderado pelo Diretor Geral. (CPAQ, 1993, art. VIII, A, 3).

A Conferência é o órgão plenário, formado por todos os membros da Organização ${ }^{3}$. É considerada como o principal órgão e sua função essencial é supervisionar a execução da Convenção, bem como promover os seus objetivos e propósitos ${ }^{4}$; o Conselho tem poderes executivos para

\footnotetext{
${ }^{1}$ A CPAC foi assinada em 1993 e entrou em vigor após o depósito do $65^{\circ}$ instrumento de ratificação (CPAQ, 1993).

${ }^{2}$ A sede da Organização está em Haia (CPAQ, 1993, art. XX),

${ }^{3}$ Os 190 Estados-membros da OPAQ representam 98\% de todo arsenal de armas químicas que existem no globo. Somente seis países não fazem da OPAQ: Israel e Mianmar não ratificaram a Convenção assinada em 1993, e Egito, Coreia do Norte, Sudão do Sul e Angola não a firmaram. $O P C W$. About $O P C W$. Disponível em: $<$ http://www.opcw.org/ about-opcw/non-member-states/>. Acesso em: 13 fev. 2015.

${ }^{4}$ Cada Estado tem direito a um voto. O quórum é de maioria dos membros e as decisões relacionadas a questões de procedimento são tomadas pela maioria simples dos presentes e
} 
implementar os termos da Convenção ${ }^{5}$ e é integrado por 41 membros eleitos pela Conferência; o Secretariado assiste o Conselho e a Conferência no desenvolvimento de suas atribuições e verifica as medidas estabelecidas pela Convenção. É formado pelo Diretor-geral, que é o líder do corpo administrativo, pelos inspetores e pelo pessoal técnico e científico. $\mathrm{O}$ Diretor-geral é eleito pela Conferência, após recomendação do Conselho, para cumprir um mandato de quatro anos, renovável uma vez (CPAQ, 1993, art. VIII, D).

Vista a arquitetura institucional da OPAQ, procede-se, então, à narrativa do caso que ensejou a jurisprudência Bustani.

Em maio de 1997, o embaixador brasileiro José Maurício Bustani foi eleito, unanimemente, pela Conferência dos Estados-membros, após recomendação do Conselho, (CPAQ, 1993, art. VIII, D, 43) para ocupar o cargo de primeiro Diretor-Geral da OPAQ, durante o período de quatro anos. O nome de Bustani foi proposto pelo governo brasileiro, em decorrência de sua exitosa carreira diplomática e sua larga experiência nos temas relacionados a organismos multilaterais e ao desarmamento (CASTRO, 2002). A propósito, Samuel Pinheiro Guimarães afirmou que "[...] o Embaixador Bustani é um dos mais inteligentes, experientes e dedicados funcionários do Itamaraty e goza de excelente reputação na diplomacia mundial." (GUIMARÃES, 2002).

votantes. As decisões sobre matérias substanciais devem ser tomadas através de consenso. Caso não seja possível atingir o consenso, aprovação se dá pelo voto afirmativo de dois terços dos membros presentes e votantes. Conforme artigo VIII, B da CPAQ. Disponível em: $<$ http://www.opcw.org/index.php?eID=dam_frontend_push\&docID=6357>. Acesso em: 13 fev. 2015.

${ }^{5}$ Os membros são eleitos para um mandato de dois anos, e são escolhidos segundo o princípio do equilíbrio geográfico e conforme a importância da sua indústria química e seus interesses em matéria de política e segurança. A composição de países obedece à seguinte orientação: nove representantes africanos; nove asiáticos; cinco da Europa Oriental; sete assentos da região da América Latina e do Caribe; dez cadeiras são da Europa Ocidental; e um membro é designado, consecutivamente, pelas regiões da Ásia e América Latina e do Caribe. As decisões em matérias substanciais são tomadas por dois terços dos membros. As questões de procedimento são decididas pela maioria simples dos membros. Conforme artigo VIII, C da CPAQ. Disponível em: <http://www.opcw.org/ index.php?eID=dam_frontend_push\&docID=6357>. Acesso em: 13 fev. 2014. 
Em 2000, um ano antes do final do seu mandato, o Diretor foi reeleito por aclamação. $\mathrm{Na}$ ocasião da eleição, o trabalho do embaixador foi fortemente elogiado, em especial pelos Estados Unidos da América (EUA). O Secretário de Estado Colin Powel, em nome de seu país, apresentou uma carta de apoio a Bustani, parabenizando-o por sua grande dedicação e pelos esforços em aplicar universalmente a Convenção (BUSTANI, 2002, p. 72).

De fato, a gestão Bustani esteve empenhada em atrair novos membros para a OPAQ na tentativa de torná-la, efetivamente, universal. Durante o seu mandato, o número de sócios aumentou de 87 para 145. O Secretariado realizou mais de 1.100 inspeções em mais de 55 Estados-partes, incluindo o Brasil, e o estoque mundial de armas químicas reduziu aproximadamente 15\% (CASTRO, 2002).

Segundo o embaixador brasileiro, os principais contornos de sua administração, foram:

[...] o tratamento não-discriminatório que dei a todos os Estados membros no âmbito da CPAQ; o apoio insistente que reivindiquei de todos os Estados membros para a OPAQ, que, junto com outras instituições multilaterais, me parecia o único caminho legítimo para regular a vida entre as nações; a busca permanente de soluções pacíficas para controvérsias, inclusive através do oferecimento dos préstimos da organização para, em cooperação com outros organismos internacionais (como o Conselho de Segurança das Nações Unidas, no caso específico do Iraque), evitar-se a possibilidade de conflitos de conseqüências inimagináveis. (BUSTANI, 2002, p. 77)

À frente da OPAQ, Bustani atuou, efetiva e reconhecidamente, em prol da universalização dos compromissos da Convenção, ao passo que negociou com países possuidores e não-possuidores de armas químicas e, principalmente, logrou o ingresso de Estados como Irã, Arábia Saudita, Sudão e Jordânia. Tais gestões foram de fundamental importância para promoção do desarmamento no Oriente Médio e, consequentemente, para a paz e segurança internacionais. 
Nessa esteira, o embaixador liderou as negociações em busca da adesão do Iraque, o que sujeitaria Bagdá ao regime de inspeções regulares e de "inspeções por desafio", que são aquelas realizadas in loco, em caráter de surpresa, por solicitação de algum Estado que considere haver indícios de descumprimento do Tratado por parte de um signatário (CPAQ, 1993, art. IX).

Entretanto, a arquitetura de poder mundial sofreu um revés em 2001, por causa dos atentados de 11 de setembro contra as torres gêmeas.

A partir de então, as iniciativas para incentivar a inclusão do Iraque à OPAQ passaram a desagradar, veementemente, a Casa Branca, já que enfraqueceriam as justificativas levantadas por Washington para consumar a ofensiva militar contra o regime de Sadam Hussein, mesmo antes de encerrado o recurso aos mecanismos de solução pacífica, de controvérsia, previsto pelo Direito Internacional ${ }^{6}$ (BUSTANI, 2002).

Consoante opina o embaixador Samuel Pinheiro Guimarães (2002),

[...] um desses pretextos, nunca comprovado, seria a posse de armas químicas e a recusa de continuar a se sujeitar às inspeções extraordinárias da UNSCOM, comissão criada após a Guerra do Golfo, que, como se sabe, eram instrumentalizadas pelos EUA, conforme o testemunho amplamente divulgado de um ex-inspetor, de nome Scott Ritter.

Nesse momento, o nome de Bustani ganha uma conotação especial e passa a protagonizar um episódio inédito na história das Organizações Internacionais.

\footnotetext{
${ }^{6}$ Segundo o embaixador Bustani, "Os Estados Unidos, mesmo durante a administração do presidente Clinton, nos últimos meses antes da finalização da Convenção, acreditavam que seria possível adaptar a OPAQ a seus projetos, interpretações e interesses específicos. Não terá sido, aliás, por outro motivo que favoreceram o estabelecimento da Organização na cidade de Haia, distante dos foros multilaterais tradicionais, como Nova York, Genebra e Viena, onde as representações diplomáticas são devidamente treinadas no delicado trabalho de negociação de acordos, inclusive - e em grande medida - nos temas de desarmamento e segurança.” (BUSTANI, 2002).
} 
Diante da recusa do brasileiro de abortar as tratativas conducentes à assinatura da Convenção por parte do Iraque e da negativa do Diretorgeral de franquear para os EUA o acesso às informações confidenciais sobre os membros, obtidas pelos inspetores da OPAQ (ADMINISTRATIVE TRIBUNAL, 2014a), o governo estadunidense, inicia uma campanha agressiva para destituir Bustani do cargo.

Em 21 de março de 2002, a delegação estadunidense submeteu à vigésima oitava sessão do Conselho Executivo uma "moção de desconfiança" convidando José Maurício Bustani a informar aos Estados-partes que renunciaria o cargo até 31 de março de 2002. A moção foi rejeitada, uma vez que não alcançou a maioria de dois terços necessários para adoção de matérias substanciais ${ }^{7}$.

Não satisfeitos, em 22 de abril de 2002, os EUA convocaram uma Conferência Especial dos Estados-partes em cuja pauta estava a deliberação sobre a cassação do mandato do Diretor-geral, com efeito imediato. Os principais argumentos levantados pelos delegados estadunidenses para exigirem a deposição do brasileiro foram: falta de transparência, má-gestão, negligência, irresponsabilidade, incompetência e desmoralização do Secretariado Técnico (UNITED STATES OF AMERICA STATEMENT, 2002). Nesta, que foi a Primeira Conferência Especial da Organização, a moção foi aprovada com 48 votos a favor, sete contrários, 43 abstenções e duas ausências. Como se vê, o voto favorável da maioria de dois terços dos presentes necessários à aprovação da decisão foi conseguido de maneira deveras curiosa, se observado o número de abstenções e votos contrários. Mas, esse resultado foi o suficiente para demitir o Diretor-Geral da OPAQ. Essa foi a primeira vez na história que o Diretor de uma Organização Internacional foi removido do seu cargo antes de completar o seu mandato.

O embaixador Bustani recebeu o apoio de diversos Estados-membros da $\mathrm{OPAQ}^{8}$, ainda que muitos delegados tenham-se mostrado intimi-

7 A moção foi apoiada por 17 Estados, cinco votaram contra e 18 se abstiveram (ADMINISTRATIVE TRIBUNAL, 2014a).

${ }^{8}$ Bustani asseverou que foi deposto "[...] apesar dos apoios que recebi pessoalmente dos representantes permanentes junto à OPAQ que admitiam encontrarem-se seus governos sob extrema pressão norte-americana, inclusive, com a ameaça dos Estados Unidos 
dados em expressar suporte necessário por conta de ameaças provenientes dos Estados Unidos. Entretanto, esse não foi o caso do governo brasileiro, que mereceu duras críticas por parte de Bustani em virtude do tímido apoio que a gestão do então presidente Fernando Henrique Cardoso the ofereceu9 (BUSTANI, 2002, p. 83).

\section{A manifestação internacional mais direta das autoridades brasileiras ocorreu na Conferência de 21-22 de abril, quando o chefe da Delegação}

de suspenderem qualquer pagamento de suas dividas para com a Organização. [...] A França, após gestão eficaz de Luís Inácio Lula da Silva, então candidato à presidência da República, junto a Lionel Jospin, dissociou-se de seu grupo e absteve-se. Com o apoio de apenas Rússia, China, Irã, Belarus, Cuba e México, diante de 43 abstenções e 48 votos "americanos", dava-se o maior golpe jamais realizado no campo das instituições multilaterais". (BUSTANI, 2002, p. 83)

${ }^{9} \mathrm{O}$ Diretor-geral atesta que "apesar de haver lutado sozinho durante cinco anos à frente da Organização, na qual serviços internacionais de inteligência procuram estar solidamente presentes, imaginava eu que, "na hora da verdade" o Brasil agiria com a firmeza e a altivez que sempre haviam caracterizado a história do meu Itamaraty. No início do processo, surpreendentemente, a chefia do Itamaraty, ao explicar sua falta de empenho - "apoio não exclamatório" - não foi capaz de entender a diferença básica entre um "funcionário internacional" (indivíduo formado e criado no quadro das organizações internacionais, sem vínculo profissional necessário com seu governo de origem) e um indivíduo eleito para ocupar cargo em organismo internacional (normalmente de chefia ou direção), por iniciativa de seu governo, manifestação de legítimo ato político, e como resultado de escolha eleitoral precedida de um processo de gestões e competição internacional. Não se passaram daí muitos dias antes que eu recebesse, de fonte norte-americana, em Haia, cópia de "aide-mémoire" entregue pela Embaixada dos Estados Unidos ao Itamaraty, em Brasília, cujo texto, reproduzido a seguir, com meu grifo, é auto-explicativo: "I am calling to express disappointment about the trend of developments in The Hague regarding the debate over the tenure of the OPCW Director-General, Mr. Bustani. We understood that Brazilian officials would vote in support of Mr. Bustani, but not lobby on his behalf. We understand the domestic pressures that are emerging in support of Mr. Bustani by virtue of his nationality. However, your diplomats are not only lobbying - which we understood Brazil would not do - but are making active attempts to block action on the U.S. proposed vote of "no confidence" through procedural maneuvers. These actions seem to us contrary to the spirit of the Secretary's (of State) March 15 conversation with Foreign Minister Lafer. In the spirit of your agreement that each EC member be free to draw its own conclusion on Mr. Bustani's performance, we would like your agreement that we proceed quickly to a vote without further hindrance or delay."' (BUSTANI, 2002, p. 83) 
brasileira na OPAQ, Embaixador Luiz Augusto de Araújo Castro, em seu discurso ressaltou o êxito da gestão Bustani, enfatizou a necessidade de se respeitar o princípio da independência das OIs e, finalmente, conclamou os Estados-partes a rejeitarem a proposta estadunidense de interrupção do mandato do Diretor-geral. Em Brasília, o Senado Federal e a Câmara de Deputados publicaram Moção de Apoio e Solidariedade ao Embaixador (CASTRO, 2002).

Nada disso foi capaz de reverter a decisão de deposição de Bustani que foi considerada como "[...] o maior golpe jamais realizado no campo das instituições multilaterais [...]” (BUSTANI, 2002, p. 83), já que revelou uma ameaça inegável à independência das Instituições multilaterais (MANBIOT, 2002).

O caso deve ser analisado no cenário da guerra contra o Iraque. O jornalista do The Guardian, George Manbiot afirma que o embaixador brasileiro era um dos obstáculos à guerra, uma vez que ele propunha a utilização de métodos pacíficos para eliminar as supostas armas químicas de Sadam Hussein. Isso bloquearia os esforços dos Estados Unidos de validarem a justificativa para uma guerra dita inevitável (STANIC, 2004, p. 814). Em artigo publicado em 16 de abril de 2002, Manbiot condenou a atuação norte-americana e advertiu que se a estratégia dos Estados Unidos de depor o Bustani fosse bem sucedida, todas as Organizações Internacionais estariam vulneráveis a ataques. Nessa esteira, ele realçou que a ação estadunidense se revelava como um acinte à independência das Instituições multilaterais (BUSTANI, 2002).

Esse caso de "inegáveis conotações políticas" (WICKREMASINGHE, 2004, p. 457) abriu um precedente perigosíssimo, principalmente, por atacar frontalmente a autonomia das OIs, e por afrontar a multilateralidade das relações internacionais. Esses foram alguns dos motivos que animaram o Embaixador a postular uma demanda contra a OPAQ no Tribunal Administrativo da OIT, consoante será exposto na continuidade. 


\section{Davi contra Golias: o contencioso Bustani versus OPAQ no Tribunal Administrativo da Organização Internacional do Trabalho}

Em 19 de julho de 2002, José Maurício Bustani impetrou uma demanda contra a OPAQ junto ao TAOIT, alegando a ilegalidade da sua demissão. O Acórdão 2232 foi proferido em 16 de julho de 2003 (ADMINISTRATIVE TRIBUNAL, 2014a).

O processo, inicialmente, levanta discussões de duas ordens fundamentais que versam sobre a competência ratione personae e a competência ratione materiae do Tribunal.

A jurisdição do TAOIT e sua competência para conhecimento do litígio encontram-se estipulados no artigo II do seu Estatuto que lhe confere poderes para "[...] receber denúncias de não cumprimento, na substância ou na forma, dos termos de nomeação de oficiais e provisões do Estatuto dos Funcionários das Organizações que reconheceram a jurisdição do Tribunal" (TAOIT, 1949). Segundo o autor da ação, a elegibilidade do Tribunal como foro competente para dirimir o contencioso estava comprovada, uma vez que a OPAQ aceitou, em 1997, a jurisdição do TAOIT para solucionar os conflitos administrativos entre a OI e seus funcionários. E, segundo preceitua o Estatuto dos Funcionários da OPAQ, “[...] os membros do Staff terão o direito de recorrer ao TAOIT contra decisões administrativas e atos disciplinares tomados [...]" (OPCW, 2001) pela Organização.

O demandante asseverou que os requisitos de admissibilidade foram cumpridos, a saber: a decisão impugnável era final, afetava seus interesses, e tinha sido tomada pela mais alta autoridade. Diante do esgotamento das possibilidades de recursos internos, não lhe restava outra alternativa senão a apelação ao Tribunal.

De acordo com alegações da parte ré, o Diretor-geral não poderia ser enquadrado como membro do staff, fato que fulminaria a competência ratione personae do Tribunal. Assim sendo, o autor não teria legitimidade ativa perante aquela Corte. Segundo considerações da OPAQ, o chefe da Organização Internacional cumpria um mandato de natureza política e não técnica, como os demais funcionários e, ademais, o Estatuto dos Ser- 
vidores seria “[...] aplicável para todos os trabalhadores designados pelo Diretor" (OPCW, 2001), fato que lhe cercearia o direito de recorrer ao TAOIT. Neste caso, uma questão inicial de ordem importantíssima que foi levantada era se o Diretor-geral poderia ser enquadrado como um funcionário normal do staff, o que lhe sujeitaria às normas de proteção trabalhista do staff, ou se, ao invés, a natureza da sua atividade era política, portanto, não se beneficiaria de tais normas.

Nessa esteira, a defesa da parte acusada externou fortes objeções sobre a admissibilidade do processo. O primeiro argumento, nesta linha, suscitava a pretensa carência de locus standi do Diretor para submeter a ação ao TAOIT, uma vez que ele não seria um membro do staff. O segundo argumento baseava-se numa suposta falta de competência ratione materiae já que a decisão impugnada seria de ordem política, portanto, não teria a índole administrativa.

O Tribunal rejeitou a interpretação da demandada, ao concluir que Bustani era enquadrado na categoria de staff member tanto do ponto de vista do Estatuto do TAOIT, como de acordo com o sentido ordinário da palavra "funcionário". Acrescentou que o Diretor é nomeado por decisão de autoridade competente que estabelece suas condições de remuneração e define suas garantias, do mesmo modo que as dos outros empregados, ao abrigo do Estatuto dos Funcionários. Por fim, asseverou que o apelante era "[...] um servidor público internacional legitimado a apelar ao Tribunal contra a decisão de cassação do seu mandato." (ADMINISTRATIVE TRIBUNAL, 2014a, p. 6). Dessa forma, a Corte afirmou sua jurisdição ratione personae.

No tocante à competência ratione materiae, a Corte sentenciou que

[...] uma decisão de interromper o mandato de um servidor civil internacional antes do seu término é uma decisão administrativa, ainda que seja baseada em argumentos políticos. O fato de ser emanada do mais alto órgão decisório não pode isentá-lo da necessária revisão aplicada para todas as decisões individuais que são alegadamente tomadas através da violação dos termos do mandato ou contrato, ou de previsões estatutárias. (ADMINISTRATIVE TRIBUNAL, 2014a, p. 6) 
Vencidos os obstáculos supracitados, o demandante, em sua defesa, expôs cinco razões, em virtude das quais a decisão que ordenou sua remoção seria considerada ilegal. Para ele, em primeiro lugar, a decisão de 22 de abril não obedeceu às regras de procedimento, o que a tornaria, portanto, inválida e nula. Em segundo lugar, a decisão era "desprovida de base legal e motivação suficiente", pois a Convenção apenas concede poderes à Conferência para nomear e renovar o mandato do Diretor-geral (após recomendação do Conselho) e não para removê-lo. A intenção do legislador, ao afastar, propositalmente, a Conferência desta incumbência foi a de assegurar a independência do Diretor-geral e blindar a sua gestão de ingerências políticas por parte dos Estados. Em terceiro lugar, por consequência, a decisão foi tomada por uma autoridade incompetente. Segundo Bustani, houve

[...] abuso de autoridade, uma vez que foi tomada (a decisão) sob pressão de um dos Estados-membros, os Estados Unidos, que havia ameaçado de suspender sua contribuição financeira à Organização se o Diretor permanecesse no cargo. (ADMINISTRATIVE TRIBUNAL, 2014a, p. 7)

O Conselho Executivo, ao rejeitar a moção de desconfiança, avalizou a gestão Bustani. Os Estados Unidos, quando solicitou a convocação de uma sessão extraordinária da Conferência dos Estados-partes, desrespeitou as regras de procedimento pois, em nenhum caso, a Conferência pode ser considerada como um órgão de apelação das decisões do Conselho. Ainda que a possibilidade de demissão decorresse de competência implícita, o poder deveria ser exercido pela Conferência, mediante recomendação do Conselho, de maneira análoga à da nomeação. Em quarto lugar, o reclamante argumentou que houve quebra dos preceitos contratuais uma vez que não havia qualquer dispositivo que autorizasse a sua deposição antes de finalizada sua gestão. A mera referência à falta de confiança como motivação para sua demissão era razão de ordem insuficiente, haja vista que ele foi eleito e reeleito unanimemente. Por último, ainda que existissem fundamentos suficientes para a sua exoneração, era imperativo que os órgãos da OPAQ respeitassem os princípios do juiz natural e do devido processo legal e lhe dessem a oportunidade para contestar as alegações 
sofridas. Ele não foi, sequer, informado quais as normas que, supostamente, teria violado para que fosse configurada a "falta de confiança".

$\mathrm{O}$ requerente discorreu sobre o que considerava como o real motivo da cassação de seu mandato. Para ele, a Conferência não agiu movida pelo interesse da Organização, mas sim em decorrência de pressões políticas estadunidenses.

Baseando-se nessa linha argumentativa, Bustani requereu a anulação da decisão e o pagamento de salários e indenização devidos pelo período de três anos e três semanas, para compensar os danos materiais e morais decorrentes do sofrimento e das angústias que lhe vitimaram.

A parte ré argumentou que não houve irregularidades no procedimento e que a falta de confiança no Diretor-geral colocara em xeque a "[...] preservação e o efetivo funcionamento da Organização [...]" (ADMINISTRATIVE TRIBUNAL, 2014a, p. 7) e, por conseguinte, constituía uma circunstância especial que justificaria à Conferência exercitar o poder de remover o Diretor. Também é enfatizado que a reeleição ocorrida um ano antes se deveu ao fato de que não havia outro candidato. A OPAQ não se manifestou a respeito da violação aos princípios do juiz natural e do devido processo legal.

Na Sentença, o TAOIT condenou as interferências políticas por parte dos Estados, em especial, dos Estados Unidos, e confirmou seu entendimento segundo o qual:

[...] a independência dos servidores públicos internacionais se constitui uma garantia não só para os servidores, mas, também, para preservar o próprio funcionamento das Organizações Internacionais. No caso dos chefes, a independência é protegida, inter alia, pelo fato de que eles são nomeados para um mandato cujo período é limitado. (ADMINISTRATIVE TRIBUNAL, 2014a, p. 7)

Ou seja, a limitação é uma forma de preservar a independência do funcionário e da Organização. Vulnerar o Diretor a mudanças e pressões políticas, e deixá-lo sujeito à demissão é uma violação inaceitável aos princípios que regem a atuação das OIs. O afastamento prematuro do 
cargo infringiu os termos do contrato dos trabalhadores e os princípios do Direito do serviço público internacional. A remoção apenas seria admissível em caso excepcional de conduta comprovadamente grave. Mas, mesmo assim, a decisão deveria ser tomada em completa observância aos princípios do devido processo e do juiz natural (ADMINISTRATIVE TRIBUNAL, 2014a).

$\mathrm{O}$ princípio da independência encontra-se plasmado no artigo VIII, D, 46 e 47 da CPAQ, que estatui que o funcionário da OPAQ não deve receber instruções de nenhum governo ou de algum setor externo à Organização. Por outro lado, os Estados devem respeitar o caráter exclusivamente internacional das responsabilidades dos funcionários internacionais e, portanto, deverão abster-se de tentativas destinadas a influenciar o Secretariado no desempenho de suas funções. O respeito a este princípio é de capital importância para a credibilidade das instituições multilaterais.

Em conclusão, o TAOIT deu provimento ao recurso, por considerar que a demissão foi ilegal e que a OI não ofereceu as garantias processuais necessárias ao demandante. Uma vez que o embaixador Bustani não pleiteou a recondução ao cargo, a OPAQ foi condenada ao pagamento de salários e emolumentos desde o dia da demissão até 12 de maio de 2005, além de indenização por danos morais arbitradas no valor de 50.000 euros.

A princípio, a OPAQ absteve-se de cumprir os termos da Sentença. Por tal motivo, o autor da ação foi induzido a recorrer ao TAOIT, solicitando a execução do Acórdão n. 2.232. O pedido foi julgado em 14 de maio de 2004, ocasião em que o Tribunal ratificou sua decisão anterior e compeliu a OPAQ a cumprir suas obrigações dela decorrentes. (ADMINISTRATIVE TRIBUNAL, 2014b). Importante registrar que Bustani doou a totalidade da indenização que recebeu ao Fundo da OPAQ de Cooperação para os Países em Desenvolvimento.

Essa foi "[...] a primeira vez na história que o TAOIT revisou a decisão de uma Organização para remover seu líder [...]" (STANIC, 2004, p. 811) antes de expirar o seu mandato.

A decisão foi extremamente importante, uma vez que reafirmou a independência das OIs e censurou um dos Estados-membros, os Estados 
Unidos, por sua interferência política malévola na vontade jurídica da Instituição multilateral.

Para se reconhecer a relevância do Acórdão do TAOIT, é necessário discorrer sobre a evolução e edificação do princípio da autonomia das Organizações Internacionais, tema que será objeto do próximo tópico.

\section{A Autonomia das Organizações Internacionais, a Deposição do Diretor-Geral e o Acordão do TAOIT}

As Organizações Internacionais são sujeitos secundários, derivados, de Direito já que devem a sua existência a ato jurídico prévio e exterior à própria Organização.

A personalidade jurídica das OI foi, primeiramente, reconhecida no Parecer Consultivo de 11 de abril de 1949 da Corte Internacional de Justiça no caso "Reparação de danos sofridos a serviço das Nações Unidas" que versava sobre o assassinato, em Israel, do diplomata sueco Conde Folke Bernadotte, enviado como mediador das Nações Unidas, por terroristas israelenses. Diante de uma consulta da Assembleia Geral a respeito da capacidade da Organização das Nações Unidas (ONU) de apresentar uma reclamação internacional contra o governo responsável pelos danos sofridos pela entidade e pelas vítimas, o Tribunal de Haia respondeu que “[...] a Organização é um sujeito de Direito Internacional que tem capacidade para ser titular de direitos e deveres internacionais." (ICJ, Reports, 1949). Além de reconhecer a personalidade jurídica de tais entes, a Corte atestou para o fato de que os Estados-membros são obrigados a respeitar o princípio da independência das OIs, consoante plasmado no artigo 100 da Carta da $\mathrm{ONU}^{10}$, com vistas a garantir o cumprimento dos objetivos

\footnotetext{
${ }^{10}$ Segundo prescreve a Carta da ONU, “[...] no desempenho de seus deveres, o SecretárioGeral e o pessoal do Secretariado não solicitarão nem receberão instruções de qualquer governo ou de qualquer autoridade estranha à organização. Abster-se-ão de qualquer ação que seja incompatível com a sua posição de funcionários internacionais responsáveis somente perante a Organização. 2. Cada Membro das Nações Unidas se compromete a respeitar o caráter exclusivamente internacional das atribuições do Secretário-Geral e do pessoal do Secretariado e não procurará exercer qualquer influência sobre eles no desempenho de suas funções".
} 
que lhes incumbem por força dos Tratados (ICJ, Reports, 1949). A partir deste momento, estava cristalizado o entendimento segundo o qual as OIs, ao lado dos Estados, eram sujeitos de DIP cuja natureza era singular e diferente daquela de seus Estados criadores.

Entre as características fundamentais desses novos sujeitos de DIP estão: a composição interestatal, base jurídica convencional, estrutura orgânica permanente e independente e a autonomia jurídica (DÍEZ DE VELASCO, 2010, p. 43-47).

A estrutura orgânica "permanente, própria e independente" de uma Organização Internacional serve para gerir os interesses coletivos, cumprir os objetivos para as quais ela foi criada, e a capacita para exprimir uma vontade juridicamente distinta daquela de seus Estados-membros (DÍEZ DE VELASCO, 2010, p. 43).

Da subjetividade das OIs decorrem algumas manifestações: capacidade de firmar tratados e de entabular relações diplomáticas (direito de legação) e direito de participar em contenciosos internacionais.

A autonomia, por sua vez, decorre da personalidade jurídica própria e se constitui como condição sine qua non para o cumprimento dos objetivos institucionais. Ademais, o princípio serve para blindar as "criaturas" das ingerências dos Estados, seus criadores.

Nessa ordem de ideias, observa-se que a autonomia pode ser vista como independência política ou independência institucional. São duas importantes dimensões que, por sua vez, não podem ser analisadas de forma isolada, desconectadas.

A independência institucional traduz-se na "[...] impermeabilidade da organização às interferências institucionais externas [...]” (D’ASPREMONT, 2011, p. 63) e na sua habilidade de se comportar como um ator independente na sociedade internacional, capaz de cumprir autonomamente as suas funções.

A independência institucional é condição primordial para configuração da identidade da OI, “[...] cuja razão de existir repousa na criação de um regime separado do geral do Direito Internacional.” (D'ASPREMONT, 2011, p. 64). A fundação de um regime próprio destinado 
ao cumprimento dos objetivos que lhe incumbem por força dos tratados constitutivos, requer um razoável grau de autonomia. Mas, é claro que é muito difícil saber qual é a extensão dessa autonomia institucional e qual a proporção da cooperação com outros sujeitos ou, até, da subordinação.

A independência política, por seu turno, está atrelada ao debate sobre a volonté distincte e a consequente permeabilidade da Organização, em função das influências estatais, as quais a Instituição pode ser alvo. A Autonomia é, assim, um conceito-chave para a independência política da OI, pois reflete a capacidade de manter-se isolada dos Estados-membros no momento da tomada de decisão, o que demonstra a sua separate will, que é derivada da sua personalidade jurídica (D'ASPREMONT, 2011, p. 63).

Entretanto, de fato, é extremamente complexo conseguir diferenciar os níveis e extensão de autonomia de um ente. Para D’Aspremont (2011, p. 64), "[...] a autonomia de uma organização internacional pode ser vista como um receptáculo de todas as contradições internas de projetos políticos e estruturas institucionais que dependem muito do contínuo suporte dos Estados-membros [...]", por isso trata-se de um conceito complexo e multifacetário. Mas, sabe-se que a autonomia se relaciona com o grau de burocratização e institucionalização.

Mas, o debate sobre a autonomia das OIs se vincula diretamente à forma como a natureza destes atores é compreendida. No terreno das Relações Internacionais há falta de consenso e são precárias as formulações sobre o comportamento das OIs. Segundo advertem Michael Barnett e Martha Finnemore (2004, p. 2), a maioria das teorizações é direcionada aos "Estados e ao comportamento do Estados [...]", e as análises tradicionais sobre as OIs colocam-nas muitas vezes em posição de marginalidade em relação aos Estados.

No âmbito das teorias chamadas clássicas, os autores realistas advogam que as OIs são criadas pelos Estados para servirem aos seus interesses, em especial aos relacionados à segurança nacional. Nesse sentido, Mearsheimer (1994, p. 7) observa que para o Realismo "[...] as Instituições internacionais são o reflexo da distribuição de poder no mundo". As grandes potências " [...] criam e modulam as Instituições para que possam 
manter sua parcela do poder mundial e, até, aumentá-la." (MEARSHEIMER, 1994, p. 7). Seguindo essa lógica, as OIs são baseadas em cálculos de interesse nacional das grandes potências e, portanto não são independentes. Esta visão sintoniza fielmente com a investida estadunidense de finalizar prematuramente o mandato do Diretor da OPAQ.

Os Institucionalistas, por outro lado, entendem que as Instituições "podem alterar as preferências dos Estados e, por consequência, mudar o comportamento nacional” (MEARSHEIMER, 1994, p. 7). Assim é que “[...] as Instituições são variáveis independentes e têm a capacidade de desviar os Estados da guerra." (MEARSHEIMER, 1994, p. 7). Entretanto, segundo esta ótica, os Estados e as OIs, enquanto atores intergovernamentais não são livres para tomadas de decisão já que os Estados cooperam para defender os interesses nacionais.

Estas teorias não dão conta de compreender que as OIs são seres que agem autonomamente, na medida em que são capazes de "[...] formular, implementar políticas que não podem ser simplesmente descritas como produto de barganha interestatal." (REINALDA; VERBEEK, 1998, p. 3.) Assim, as OIs aprovam e implementam normas para resolver problemas, desenvolvem rotinas, definem suas agendas e "[...] utilizam-se destas regras, não apenas para regular, como, também, para constituir e construir o mundo social." (BARNETT; FINNEMORE, 2004, p. 2). O socioconstrutivismo ao considerar as OIs a partir de seu caráter transnacional (ao invés de intergovernamental), e vislumbrá-las como burocracias internacionais consegue atestar a autonomia destas Instituições e se alinhar ao posicionamento do TAOIT e das esferas jurídicas internacionais. Embora sejam criações dos Estados, as OIs são capazes de instituir agendas, regras e valores sociais e de implantar políticas de caráter independente, na medida em que operam como burocracias que agem segundo a legitimação de uma autoridade própria que formula normas e executa agendas. Tais organizações podem "[...] atuar como administrações nacionais, implementar tarefas governamentais e ainda promover, estabelecer e desenvolver novos Estados.” (ANDREEV, 2007).

Têm razão Barnett e Finnemore (2004, p. 5) quando advogam que as Instituições, como burocracias “[...] não são apenas servos para quem 
os Estados delegam. Burocracias são, também, autoridades no seu próprio direito, e esta autoridade dá-lhes autonomia frente a Estados, indivíduos e outros atores de Direito Internacional". Autoridade, por sua vez, é a “[...] habilidade de um ator de usar recursos institucionais e discursivos para provocar respeito por parte de outros." (BARNETT; FINNEMORE, p. 6). E a autonomia é o elemento constitutivo da personalidade jurídica das Organizações.

Essa interpretação põe em evidencia que o Acórdão n. 2.232 foi prolatado oportunamente, diante de um contexto complexo que refletia a "[...] necessidade urgente de desenvolver novos procedimentos e mecanismos para assegurar que as organizações internacionais e seus funcionários permaneçam imunes a tais interferências." (STANIC, 2004, p. 814).

O julgado Bustani tornou-se emblemático porque levantou uma série de questões relativas ao Direito Internacional Público e ao funcionamento das Organizações Internacionais. O procedimento que autorizou a deposição do embaixador foi completamente eivado de vícios desde a sua origem até a aprovação da decisão impugnada. A Corte, além de considerar ilegal a demissão do Embaixador, desnudou as tratativas de manipulação da volonté distincte da OI, por meio da utilização de estratégias destinadas à imposição do interesse nacional estadunidense, como as ameaças de cancelamento das suas contribuições financeiras à OPAQ, caso o Diretor-geral não fosse afastado e, também, de cessação do financiamento destinado à participação de delegações de alguns países na Conferência que deliberou sobre a moção de desconfiança.

A deposição do brasileiro representou um insulto frontal à autonomia, enquanto elemento constitutivo da personalidade jurídica das Organizações.

O caso Bustani deve ser examinado no contexto da guerra do Iraque. Quando se alarga o ângulo de análise, chega-se à conclusão que a ação estadunidense iniciada nas Instituições da OPAQ e cujo ápice se deu na invasão ilegal ao Iraque, foi capaz de ultrajar vários princípios catalogados e cristalizados pelo Direito Internacional. O ataque à independência da OI reverberou em forma de um desacato generalizado a diversos 
princípios de Direito das Gentes que vêm sendo consolidados há séculos, tais como a igualdade jurídica, a boa-fé, o multilateralismo, a soberania, a solução pacífica de controvérsias e a não intervenção em assuntos internos. Também, conforme evidenciado pelo Acórdão n. 2.232, houve transgressão ao devido processo legal e à pretensão de negar ao Diretor-geral o acesso à justiça.

O princípio da igualdade, cujas raízes se assentam na Paz de Westfália de 1648, se transformou, junto com a independência e a soberania, em um dos três direitos fundamentais dos Estados. Ele foi reconhecido formalmente pela Carta de São Francisco e por outros instrumentos normativos internacionais, como a Carta de Direitos e Deveres Econômicos dos Estados, a Declaração Relativa aos Princípios do Direito Internacional Referentes às Relações de Amizade e à Cooperação e a Convenção Pan-americana sobre os Direitos e Deveres dos Estados, entre outras.

A igualdade é a coluna vertebral do sistema multilateral e o pilar fundador da nova ordem mundial.

O baiano Rui Barbosa, um dos percussores da tradição doutrinária que conduziu à aceitação universal da igualdade jurídica entre Estados como direito vital ${ }^{11}$, em discurso proferido na II Conferência de Paz de Haia, em 1907, verbalizou:

Por certo que entre os Estados, como entre indivíduos, diversidades há de cultura, probidade, riqueza e força. Mas daí derivará, com efeito, alguma diferença no que lhes entende com os direitos essenciais? [...]. Até agora os Estados, tão diversos na extensão do território, na riqueza, na força, tinham entre eles, todavia, um ponto de comensurabilidade moral. Era a soberania nacional. Sobre

\footnotetext{
11 "Ao defender as potências menores em Haia, Rui ao mesmo tempo condenava, ainda que implicitamente, o caráter oligárquico da hegemonia das grandes potências, cujo poder de influência e de decisão residia, sobretudo, na capacidade que tinham de uso da força. Não que se deixasse de reconhecer desigualdades de fato entre Estados. Visava-se, sim, ao reconhecimento da igualdade de direito para assegurar, em moldes liberais, a eqüidade na representação formal das soberanias. Subjacente ao pensamento barbosiano estava, portanto, a ideia de superação das relações assimétricas de poder por novas formas ideais de interação diplomática, nas quais o estatuto igualitário entre os atores seria o dado essencial". (GARCIA, 1996, p. 118-119)
} 
esse ponto sua igualdade jurídica estabelecer-se-ia de uma maneira inquebrantável. Nesta fortaleza de um direito igual para todos, e igualmente inviolável, inalienável, indiscutível, cada Estado, grande ou pequeno, sentir-se-ia tão senhor de si mesmo e tão seguro em relação aos outros, quanto o cidadão livre entre os muros de sua casa. (BARBOSA, 1907)

Da igualdade, derivam a não intervenção e a não ingerência em assuntos internos, princípios frontalmente agredidos com a invasão ao Iraque. O uso do aparato público internacional para defender interesses particulares, ofendeu, também, o princípio da boa-fé que impede que um agente atue de modo a favorecer a si próprio.

A deposição do chefe da Organização colocou em cheque os pilares do multilateralismo construído depois da Segunda Guerra Mundial. A atitude hipócrita do governo dos Estados Unidos desrespeitou os preceitos do Direito Internacional Público, reafirmou o apego ao poder, e fez valer o já banido recurso à força como mecanismo de solução de controvérsias. A sequência de atos, do mesmo modo, deixou desabar a desfaçatez escancarada no descumprimento reiterado dos preceitos que a sociedade elegeu para reger a ordem internacional. Na contramão, a Sentença do Tribunal da OIT demarca o esforço de preservar todo o catálogo de princípios, em especial a multilateralidade e a autonomia, na medida em que atestou que a gestão do Diretor-geral obedeceu aos princípios de independência e não discriminação, ao passo que ele cumpriu a determinação de não receber instruções de nenhum governo, nem mesmo do brasileiro.

Neste diapasão, vale ressaltar ainda que, mesmo que o TAOIT não tenha competência para julgar a atuação abusiva dos Estados Unidos neste caso em concreto, já é reconhecido pela doutrina que o Estado pode ser responsabilizado por violar a personalidade jurídica da Organização no processo de tomada de decisões (D’ASPREMONT, 2007, p. 91-119).

Dado o exposto, confirma-se a relevância do Acórdão n. 2.232, por ter gerado um relevante precedente jurídico que significou mais uma ferramenta em favor do Direito das Organizações Internacionais, ao passo que protegeu a independência, preservou a expressividade da volonté dis- 
tincte das Instituições e se constituiu como mais um passo rumo à solidificação do sistema multilateral.

\section{Conclusão}

A vertiginosa multiplicação do número das OIs atesta para a relevância de seu papel como atores de governança global com capacidade de conduzir os grandes temas globais, ao passo que reafirma a tradição de solução pacífica de controvérsias por meio do recurso aos mecanismos entabulados pela diplomacia parlamentar.

O desenvolvimento das OIs acompanha pari passu a evolução da sociedade internacional e a generalização da consciência acerca da necessidade de atuação coletiva para resolução de problemas comuns. Ao mesmo tempo, o fortalecimento das instituições multilaterais marca a nova arquitetura internacional, inaugurada no pós-segunda guerra a partir da fundação da ONU, que estimulou o empoderamento destes atores na medida em que alargou a sua esfera de competências a fim de possibilitar a realização de novas funções, as quais os Estados se mostraram incapazes de executar isoladamente.

O Parecer da Corte Internacional de Justiça de 1949 representa para as OIs a saída da zona periférica e sua transformação em atores de primeira grandeza das Relações Internacionais, dotados de personalidade jurídica e autonomia frente aos entes estatais.

Ainda assim, a independência desses atores que têm sido alvo de constantes ataques por parte de alguns Estados, ainda viciados com os ranços do estatocentrismo. Este complexo ambiente internacional exige a realização de complexas (e crescentes) tarefas destinadas a garantir a estabilização e a previsibilidade do cenário mundial. É nesse campo que as OI laboram e lutam para, de um lado, maximizarem sua eficiência e, de outro lado, para preservarem a sua independência, constantemente desafiada pelas vertentes realistas.

A demissão precoce do representante máximo de uma OI capitaneada pelo governo dos Estados Unidos foi uma ação sem precedentes na 
história das Organizações Internacionais e colocou em risco os alicerces do sistema multilateral edificado sobre os escombros das duas grandes guerras mundiais.

A ação sem precedentes recebeu uma resposta, do mesmo modo, corajosa do Tribunal. Consoante visto, foi a primeira vez que uma Corte Internacional declarou ilegal a remoção do mais alto funcionário de uma OI.

Como se sabe, a jurisprudência é uma ferramenta importante para a consolidação de normas e princípios do DIP. O Acórdão n. 2.232, em particular, reforçou a independência e a autonomia como instrumentos de salvaguarda das OIs contra agressões nacionais, haja vista que tais princípios procuram impedir que Estados manipulem a Organização para satisfazerem os interesses domésticos.

A autonomia é a raison d'être das OIs e funciona como um reflexo defensivo das Instituições multilaterais. Dela decorrem consequências jurídicas: em primeiro lugar, a vontade jurídica da OI não pode se confundir com a vontade dos Estados. Assim sendo, o Direito nascido das OIs é proveniente de uma fonte autônoma; em segundo lugar, o caráter autônomo é fundado na existência de órgãos próprios e independentes, os quais formulam regras e são capazes de implementar agendas. Por outro lado, tal autonomia reclama uma constante interação com os Estados nacionais tanto no plano da elaboração, quanto da execução de algumas normas, o que, de nenhum modo possibilita a usurpação dos poderes e a minimização da capacidade de atuação das Organizações.

Por último - e ainda reforçando a importância da jurisprudência Bustani - é imperativo evidenciar que a vulneração aos princípios do Direito das Organizações Internacionais representa não apenas a transgressão a um mandamento normativo em específico, mas a todo um sistema de comandos. Tal ilegalidade é a mais grave forma de ofensa porque significa a insurgência contra todo o sistema multilateral, a subversão de seus valores nucleares e a corrosão de sua estrutura-mestre, já que os princípios representam os mais altos valores de civilidade. 


\section{Referências}

\section{ANDREEV, Alexander. To what extent are International}

Organizations (IOS) autonomous actors in world politics? 2007.

Disponível em: <http://www.ucl.ac.uk/opticon1826/archive/issue2/VfPS HS_International_Organisations.pdf $>$. Acesso: 12 maio 2015.

BARBOSA, Rui. O novo Tribunal Permanente de Arbitragem. Primeira Comissão, oitava sessão, 9 de outubro de 1907. In: BRIGAGÃO, C; FERNANDES, F. (Org.) Diplomacia brasileira para a paz. Brasília: Funag, 2012. p. 57-67.

BARNETT, Michael; FINNEMORE, Martha. Rules for the world. London: Cornell University Press, 2004.

The Politics, Power and Pathologies of International

Organizations. International Organization, [S.l.], v. 53, n. 4, p. 699$732,1999$.

BUSTANI, José Mauricio. O Brasil e a OPAQ: diplomacia e defesa do sistema multilateral sob ataque. Estudos avançados, [S.l.], v. 16, n.46, p. 69-84, dezembro de 2002. Disponível em: $<$ http://www.scielo.br/scielo. php?pid $=$ S0103-40142002000300006\&script $=$ sci_arttext $>$. Acesso: 14 fev. 2014.

CASTRO, Luiz Augusto de Araujo. Statement by Ambassador Luiz Augusto de Araujo Castro, Under-secretary for Multilateral Political Affairs Head of the Delegation of Brazil to the Special Conference of the States Parties to the Chemical Weapons Convention. The Hague, [S.l.], p. 21-22, april, 2002. Disponível em: <http://www.opcw.org/index. php? $\mathrm{eID}=$ dam_frontend_push\&docID=5111>. Acesso: 20 fev. 2013.

COLLINS, R.; WHITE, N. D. International Organizations and the idea of autonomy. Oxford: Routledge, 2011.

CONVENÇÃO PARA A PROIBIÇÃO DAS ARMAS QUÍMICAS (CPAQ). Convention on the Prohibition of the Development, Production, Stockpiling and Use of Chemical Weapons and on their Destruction. [2014]. Disponível em: <http://www.opcw.org/index. php?eID=dam_frontend_push\&docID=6357>. Acesso: 13 fev. 2014. 
D'ASPREMONT, Jean. The Multifaceted Concept of the Autonomy of International Organizations and International Legal Discourse.

Manchester: University of Manchester - School of Law, 2011.

D'ASPREMONT, Jean. Abuse of the Legal Personality of International Organizations and the Responsibility of Member States. International Organizations Law Review, [S.l.], v. 1. 4, p. 91-119, 2007.

DIEZ DE VELASCO, Manuel. Las organizaciones internacionales. 16. ed. Madrid: Tecnos, 2010.

GARCIA, Eugênio Vargas. Aspectos da vertente internacional do pensamento político de Rui Barbosa. Textos de História, [S.l.], v. 4, n. 1, p. 103-124, 1996.

GUIMARÃES, Samuel Pinheiro. O Brasil, os Estados Unidos, a OPAQ e Bustani. Resistir Info. [S.l.], 2002. Disponível em: <http://resistir.info/ varios/opaq_spguimaraes.html>. Acesso: 25 fev. 2014.

INTERNATIONAL LABOUR ORGANIZATION (ILO). The Tribunal. [2013]. Disponível em: <http://www.ilo.org/public/english/tribunal/ about/index.htm. Acesso em 23/11/2013>. Acesso: 23 nov. 2013.

INTERNATIONAL LABOUR ORGANIZATION (ILO). Administrative Tribunal. Ninety-fifty session. Judgment 2.232. [2014a]. Disponível em: <http://www.ilo.org/dyn/triblex/triblexmain.fullText?p_lang=en\&p_ judgment_no=2232\&p_language_code=EN. >. Acesso: 25 fev. 2014.

. Ninety-seventh session. Judgment 2.328. [2014b]. Disponível em: <http://www.ilo.org/dyn/triblex/triblexmain.fullText?p_lang=en\&p_ judgment_no=2327\&p_language_code=EN>. Acesso: 25 fev. 2014.

MEARSHEIMER, John. The False Promise of International Institutions. International Security, [S.l.], v. 19, n. 3, p. 5-43, 1994/5. Disponível em: <http://mearsheimer.uchicago.edu/pdfs/A0021.pdf $>$. Acesso em: 22 abr. 2014.

MANBIOT, G. A War Against the Peacemaker. 2002. Disponível em $<$ http:/www.monbiot.com/2002/04/16/a-war-against-the-peacemaker/ >. Acesso: 28 abr. 2015. 
ORGANIZAÇÃO DAS NAÇÕES UNIDAS. Carta das Nações Unidas e Estatuto da Corte Internacional de Justiça. 26 junho, 1945. Disponível em: $<$ http://unicrio.org.br/img/CartadaONU_VersoInternet. pdf $>$. Acesso em: 15 maio 2015.

ORGANIZATION FOR THE PROHIBITION OF CHEMICAL WEAPONS. Convention on the Prohibition of the Development, Production, Stockpiling and Use of Chemical Weapons and on their Destruction. 1993. Disponível em: $<\mathrm{http}: / / \mathrm{www} . o p c w . o r g / i n d e x$. php?eID=dam_frontend_push\&docID=6357.>. Acesso em: 13 fev. 2014.

. About OPCW. 2015. Disponível em: $<$ http://www.opcw.org/ about-opcw/> e <http://www.opcw.org/about-opcw/>. Acesso em: 14 fev. 2015.

. Statement by the Director-General at the Special Session of the Conference of the States Parties. C-SS-1/DG.7. 21 de abril de 2002. Disponível em: $<$ http://www.opcw.org/index.php?eID=dam_frontend_ push\&docID=5101>. Acesso 26 fev. 2014.

. Staff Regulations and Interim Staff Rules of the Technical Secretariat of the Organization for the Prohibition of Chemical Weapons. [2014]. Disponível em $<\mathrm{https} / / / \mathrm{www} . o p c w . o r g / i n d e x$. php?eID=dam_frontend_push\&docID $=13387>$. Acesso em: 24 mar. 2014.

PATRÃO, Afonso Nunes de Figueiredo. O Tribunal Administrativo das Nações Unidas. Boletim da Faculdade de Direito, Coimbra. LXXXII, p. 639-693, 2006.

REINALDA, Bob; VERBEEK, Bertjan. Autonomous policy-making by International Organizations. London/New York: Routledge, 1998.

SILVA, Karine de Souza; COSTA, Rogério. Organizações

Internacionais de Integração Regional: União Europeia, Mercosul e UNASUL. Florianópolis: EdUFSC, 2013.

STANIC, Ana. Bustani v. Organization for the Prohibition of Chemical Weapons. Judgement n. 2.232. The American Journal of Law. [S.l.], v. 98, p. 810-814, 2004. 
UNITED STATES OF AMERICA. United States of America statement for Special Conference of States Parties to the Organization for the Prohibition of Chemical Weapons. C-SS-1/NAT.1. 21 de abril de 2002. Disponível em: $<$ http://www.opcw.org/index.php?eID=dam_frontend_ push\&docID=5113>. Acesso em: 26 fev. 2014.

WICKREMASINGHE, Chanaka. The Bustani Case before the ILOAT. International Organizations Law Review, [S.l.], p. 197-207, 2004.

Karine de Souza Silva é pesquisadora Produtividade em Pesquisa CNPq, professora dos Programas de Mestrado e Doutorado em Direito e em Relações Internacionais da Universidade Federal de Santa Catarina (UFSC), titular da Cátedra Jean Monnet - outorgada oficialmente pela União Europeia, doutora e mestre em Direito pela UFSC, professora visitante da Universidade Técnica de Moçambique (Moçambique), da Universidade do Minho (Portugal), e da Universidad de Valladolid (Espanha), consultora ad hoc do CNPq, da CAPES, da FAPESC, do MEC e da União Europeia, coordenadora do EIRENÈ (Núcleo de Pesquisas e Extensão sobre as Organizações Internacionais e a promoção da Paz, dos Direitos Humanos e da Integração Regional) e do Núcleo de Apoio a Imigrantes e Refugiados (NAIR/Eirenè/UFSC). Fez estágio doutoral na Universidad de Sevilla (Espanha) e estágio pós-doutoral em Relações Internacionais na Katholieke Universiteit Leuven (Bélgica). Possui pós-graduação lato sensu em Integração Regional na Universidad Internacional de Andalucía (Espanha).

E-mail: karine.silva@ufsc.br

Endereço profissional: Universidade Federal de Santa Catarina, Centro de Ciências Jurídicas, Campus Trindade, Trindade, Florianópolis, SC. Brasil. CEP: 88040-900. 
